\title{
Quantitative Analysis of Hispidulin Content in Clerodendrum petasites Roots Distributed in Thailand
}

\author{
Thanyathorn Tangsongcharoen ${ }^{1}$, Somchai Issaravanich ${ }^{1}$, Chanida Palanuvej ${ }^{1, *}$, Nijsiri Ruangrungsi ${ }^{1,2}$
}

\section{Thanyathorn \\ Tangsongcharoen ${ }^{1}$, \\ Somchai Issaravanich', \\ Chanida Palanuvej ${ }^{1, *}$, Nijsiri \\ Ruangrungsi ${ }^{1,2}$}

'Public Health Sciences Program, College of Public Health Sciences, Chulalongkorn University, Bangkok 10330, THAILAND. ${ }^{2}$ Department of Pharmacognosy, College of Pharmacy, Rangsit University, Pathum Thani 12000, THAILAND.

\section{Correspondence}

Assoc. Prof. Chanida Palanuvej, Ph.D.

College of Public Health Sciences,

Chulalongkorn University, Bangkok 10330, THAILAND.

Phone no: +662-218-8158;

E-mail: chanida.p@chula.ac.th

History

- Submission Date: 16-05-2019;

- Review completed: 28-05-2019;

- Accepted Date: 04-06-2019.

DOI : 10.5530/pj.2019.11.171

Article Available online

http://www.phcogj.com/v11/i5

Copyright

(C) 2019 Phcogj.Com. This is an open access article distributed under the terms of the Creative Commons Attribution 4.0 International license.

\begin{abstract}
Introduction: Clerodendrum petasites (Lour.) S. Moore (locally known as Mai-Thao-Yaai-Mom) belonging to the Verbenaceae family, is widely formulated into multi-herb remedy, Ben-ChaLo-Ka-Wi-Chian remedy, possessing antipyretic activity. C. petasites exhibits many biological activities, such as antioxidant, anti-inflammatory, antipyretic, etc. The flavonoid hispidulin is one of the main active compounds present in $C$. petasites, containing anti-atheromatous, antitumor and antispasmodic effects. Objective: The present study aimed to determine the hispidulin content in the dried roots of $C$. petasites using HPLC technique. Methods: C. petasites dried roots, collected from twelve different areas, were extracted with ethanol using Soxhlet apparatus, and then subjected to HPLC-PDA to quantify hispidulin content. The quantitative method using HPLC-PDA technique was validated. Results: The optimized HPLC coupling with PDA detector (HPLC-PDA) was validated for the quantitative analysis of hispidulin content in $C$. petasites roots in terms of linearity $\left(y=210,200,536.6667 x-448,756.2667 ; R^{2}=\right.$ 0.9997), accuracy (88.82-107.69\% recovery), precision (0.66\% RSD for repeatability precision; $1.17 \%$ RSD for intermediate precision), limit of detection $(2.30 \mu \mathrm{g} / \mathrm{mL})$, limit of quantitation $(7.00 \mu \mathrm{g} / \mathrm{mL})$, specificity (peak purity index $=1.0000)$ and robustness $(\% \mathrm{RSD}<1)$. The amount of hispidulin content in the extracts of $C$. petasites roots conducted from the validated method was found to be $0.0182 \pm 0.0109 \mathrm{~g} / 100 \mathrm{~g}$ crude drug. Conclusion: The HPLC-PDA analysis was able to effectively determine hispidulin in $C$. petasites roots. The hispidulin contents in $C$. petasites dried roots from various areas in Thailand were revealed which could be used for the specification of this crude drug with reference to its chemical marker.
\end{abstract}

Key words: Clerodendrum petasites, Ben-Cha-Lo-Ka-Wi-Chian remedy, hispidulin, HPLC-PDA

\section{INTRODUCTION}

For decades, herbal plants have been used medicinally all around the world, being an important aspect of various traditional medicine systems. In Thai traditional system, Clerodendrum petasites (Lour.) S. Moore, locally known as MaiThao-Yaai-Mom, belonging to the Verbenaceae family, is widely formulated into multi-herb remedy. The most famous remedy is Ben-ChaLo-Ka-Wi-Chian (or so-called Ya-Ha-Rak, KaewHa-Dueng or Phed-Sa-Wang) remedy, which has been registered by the Thai Food and Drug Administration (FDA) for antipyretic activity. ${ }^{1,2}$

Clerodendrum petasites exhibits many biological activities, including antioxidant, anti-inflammatory, antimicrobial, antipyretic, antispasmodic and antibacterial activities. ${ }^{2,3-7}$ The biological activities have been scholarly informed to be associated with the chemical constituents. The flavonoid hispidulin (also known as 4',5,7-Trihydroxy-6methoxyflavone) (Figure 1) is one of the main active compounds present in C. petasites. ${ }^{2,5}$ Hispidulin has been reported not only for its antiatheromatous effect ${ }^{8}$ and antitumor potential ${ }^{9}$ but also for relaxation of the tracheal smooth muscles. ${ }^{5}$

To identify and isolate active constituents in medicinal plants, chromatographic techniques are<smiles>COc1c(O)cc2oc(-c3ccc(O)cc3)cc(=O)c2c1O</smiles>

Figure 1: Chemical structure of hispidulin.

world-widely used in various studies. Such technique is high performance liquid chromatography (HPLC) that is commonly used for analytical purposes, both quantitatively and qualitatively. ${ }^{10}$ HPLC is characterized by the use of high pressure to force a mobile phase solution through a column of stationary phase, allowing separation of complex mixture with high resolution by the differences in their partition and adsorption behaviors between the mobile phase and the stationary phase. ${ }^{11,12}$

Practically, the method is conducted on reversephased column (i.e., $\mathrm{C}_{18}$ ) with more polar mobile phase (e.g., water, methanol, acetonitrile). ${ }^{7,13,14}$ Although hispidulin has been highlighted for different biological properties, no report has been made on its quantification in C. petasites, particularly

Cite this article: Tangsongcharoen T, Issaravanich S, Palanuvej C, Ruangrungsi N. Quantitative Analysis of Hispidulin Content in Clerodendrum petasites Roots Distributed in Thailand Pharmacog J. 2019;11(5):1093-9. 
on its roots. As a consequence, the present study aimed to determine the hispidulin content in the dried roots of $C$. petasites using HPLC technique.

\section{MATERIALS AND METHODS}

\section{Chemicals and reagents}

Hispidulin (Sigma-Aldirch, USA, SML0582, $\geq 98 \%$ ), acetic acid glacial (BDH Chemicals, UK), AR grade ethanol, HPLC grade acetonitrile and methanol (RCI Labscan Ltd., Thailand), Ultrapure water obtained from water purification system (Brinkmann, USA)

\section{Instrumentation and equipment}

Shimadzu HPLC LC-20A, consists of auto-sampler (SIL-20A HT), HPLC column oven (CTO-20AC), HPLC degasser (DGU-20A $)$, HPLC LC-20A system, HPLC photodiode array (PDA) detector (SPD-M20A), HPLC system controller (CBM-20A), HPLC two-solvent delivery unit (LC-20AD) (Shimadzu, Japan), HPLC guard column $(5 \mu \mathrm{m}, 2.1 \times 50$ $\mathrm{mm})(\mathrm{CN}-3)$ and HPLC reversed-phased $\mathrm{C}_{18}$ column $(5 \mu \mathrm{m}, 2.1 \times 250$ $\mathrm{mm}$ ) (ODS-3) (Inertsil, GL Sciences Inc., Japan), water bath, water purification system (Brinkmann, USA).

\section{Plant collection}

Clerodendrum petasites roots from twelve different areas throughout Thailand were authenticated by Assoc. Prof. Dr. Nijsiri Ruangrungsi (Table 1). The voucher specimens were deposited at the College of Public Health Sciences, Chulalongkorn University, Thailand.

\section{Plant extraction}

Each root sample was cleaned, dried and grounded to powder (sieve number 60$)$. The powder ( $5 \mathrm{~g})$ was then exhaustively extracted with $95 \%$ ethanol $(300 \mathrm{~mL})$ by Soxhlet apparatus. After filtration, the filtrate was evaporated at $55-60^{\circ} \mathrm{C}$ using water bath till dryness. The extract was weighed to calculate the \% yield, and then dissolved in methanol $(1 \mathrm{~mL})$ to obtain a final concentration. The extract in methanol was diluted to various concentrations and filtered through $0.45 \mu \mathrm{m}$ PTFE membrane syringe filter for further HPLC analysis.

\section{Standard preparation}

The stock solution of hispidulin was prepared by dissolving the standard hispidulin $(1 \mathrm{mg})$ in methanol $(1 \mathrm{~mL})$. The solution was filtered through $0.45 \mu \mathrm{m}$ PTFE membrane syringe filter.

\section{Chromatographic condition of HPLC}

HPLC system control and data analysis were carried out by Shimadzu LC Solution software. The chromatographic separation was conducted using the reversed-phased $\mathrm{C}_{18}$ column coupled with HPLC guard column. The chromatographic condition was demonstrated as shown in Table 2. Each sample was analyzed in triplicate.

\section{Method validation}

Linearity, accuracy, precision, limit of detection, limit of quantitation, specificity and robustness were evaluated according to the Validation of Analytical Procedures. ${ }^{15}$

\section{Linearity}

The linearity of the method was expressed as a calibration range generated by plotting peak areas versus concentrations of standard hispidulin. The coefficient of determination $\left(\mathrm{R}^{2}\right)$ was calculated using Excel software.
Table 1: Areas and voucher specimen numbers of Clerodendrum petasites root collection.

\begin{tabular}{ccc}
\hline No. & $\begin{array}{c}\text { Area of C. petasites root } \\
\text { collection }\end{array}$ & Voucher specimen number \\
\hline 1 & Yasothon & CPTT01/2017 \\
2 & Lopburi & CPTT02/2017 \\
3 & Nakhon Nayok & CPTT03/2017 \\
4 & Phuket & CPTT04/2017 \\
5 & Lampang & CPTT05/2017 \\
6 & Nong Khai & CPTT06/2017 \\
7 & Phetchabun 1 & CPTT07/2017 \\
8 & Phetchabun 2 & CPTT08/2017 \\
9 & Chachoengsao & CPTT09/2017 \\
10 & Chaiyaphum & CPTT10/2017 \\
11 & Rayong & CPTT11/2017 \\
12 & Nakhon Pathom & CPTT12/2017 \\
\hline
\end{tabular}

\section{Table 2: Chromatographic condition of HPLC.}

\begin{tabular}{|c|c|c|c|}
\hline Parameter & \multicolumn{3}{|c|}{ Condition } \\
\hline $\begin{array}{c}\text { Column } \\
\text { (Stationary phase) }\end{array}$ & \multicolumn{3}{|c|}{ Reversed phase: $\mathrm{C}_{18}$} \\
\hline \multirow{11}{*}{ Mobile phase } & \multicolumn{3}{|c|}{ Solvent (A) - acetonitrile } \\
\hline & \multicolumn{3}{|c|}{$\begin{array}{l}\text { Solvent }(\mathrm{B})-0.1 \% \text { aqueous acetic acid } \\
\text { : acetonitrile }(\mathrm{v} / \mathrm{v}, 80: 20)\end{array}$} \\
\hline & \multicolumn{3}{|c|}{ Mode: Gradient elution } \\
\hline & (A) & (B) & Time \\
\hline & $0 \%$ & $100 \%$ & $9 \min$ \\
\hline & $0 \rightarrow 50 \%$ & $100 \rightarrow 50 \%$ & $6 \mathrm{~min}$ \\
\hline & $50 \%$ & $50 \%$ & $5 \mathrm{~min}$ \\
\hline & $50 \rightarrow 94 \%$ & $50 \rightarrow 6 \%$ & $10 \mathrm{~min}$ \\
\hline & $94 \%$ & $6 \%$ & $5 \mathrm{~min}$ \\
\hline & $0 \%$ & $100 \%$ & $20 \min$ \\
\hline & \multicolumn{2}{|c|}{ Total } & $55 \mathrm{~min}$ \\
\hline Flow rate & \multicolumn{3}{|c|}{$0.5 \mathrm{~mL} / \mathrm{min}$} \\
\hline Injection volume & \multicolumn{3}{|c|}{$20 \mu \mathrm{L}$} \\
\hline Column oven temp. & \multicolumn{3}{|c|}{$35^{\circ} \mathrm{C}$} \\
\hline Detector & \multicolumn{3}{|c|}{ PDA detector, $\lambda_{\max } 337 \mathrm{~nm}$} \\
\hline
\end{tabular}

\section{Accuracy}

The spike method was performed for accuracy. Different levels of standard hispidulin (low, medium and high) were spiked into the extracted sample in triplicate and the \% recovery was calculated by the following formula:

$\%$ Recovery $=\frac{A}{B+C} \times 100$

Where, $\mathrm{A}=$ the amount of hispidulin found in spiked extracted sample

$\mathrm{B}=$ the amount of hispidulin found in un-spiked extracted sample

$\mathrm{C}=$ the amount of standard hispidulin actually added to the extracted sample

\section{Precision}

The repeatability (intra-day) and intermediate (inter-day) precision examinations were assessed by analyzing the sample solution with three concentrations (low, medium and high) (each in triplicate) on the same 
day and three different days, respectively. The precision of hispidulin content analysis was determined in terms of percent relative standard deviation (\% RSD) by the following equation:

$\% \operatorname{RSD}=\frac{\mathrm{SD}}{\text { Mean }} \times 100$

\section{Limit of detection}

The limit of detection (LOD), the lowest concentration that can be detected but not necessarily quantitated as an exact value, was determined from the calibration curve using the following formula:

LOD $=\frac{3.3(\text { residual SD) }}{S}$

Where, residual $\mathrm{SD}=$ the residual standard deviation of regression line $\mathrm{S}=$ the slope of regression line

\section{Limit of quantitation}

The limit of quantitation (LOQ), the lowest concentration that can be quantitated as an exact value, was calculated from the calibration curve using the following formula:

$\mathrm{LOQ}=\frac{10 \text { (residual SD) }}{\mathrm{S}}$

Where, residual $\mathrm{SD}=$ the residual standard deviation of regression line $\mathrm{S}=$ the slope of regression line

\section{Specificity}

The specificity of the method was determined by analyzing absorbance spectra of standard hispidulin and samples. Peak purity was evaluated by comparing its peak at peak start, peak apex and peak end position.

\section{Robustness}

A small variation on the column oven temperature, from $34-36^{\circ} \mathrm{C}$, was applied for the robustness. The result was expressed as \% RSD.

\section{Data analysis}

The data were assessed by comparing the area under peak chromatogram with the calibration curve. The area under peak was analyzed using Shimadzu LC Solution software.

\section{RESULTS AND DISCUSSION}

According to the European Medicines Agency (EMA), the phytochemical compounds are commonly considered as the chemical marker, and their quantification usually indicates the quality of the plant materials due to the therapeutic activities. ${ }^{16}$ For the analysis of flavonoid using HPLC technique, binary elution system is widely performed. An aqueous acidified polar solvent (e.g., aqueous acetic acid, perchloric acid, phosphoric acid or formic acid) is used as the first solvent, while another solvent is a less polar organic solvent (e.g., acetonitrile or methanol). ${ }^{13}$ The condition of solvent system used in this study was practically consistent with the previous reports. ${ }^{7,13,17}$

The optimized HPLC coupling with PDA detector (HPLC-PDA) was validated for the quantitative analysis of hispidulin content in C. petasites roots in terms of linearity, accuracy, precision, limit of detection, limit of quantitation, specificity and robustness. The range of absorbance (200-800 nm) was screened for detection of hispidulin. The maximum wavelength of hispidulin was found to be at $337 \mathrm{~nm}$. For linearity, the calibration curve of standard hispidulin in the range of $20-100 \mu \mathrm{g} / \mathrm{mL}$ was generated with the regression equation of $y=210,200,536.6667 x$ - 448,756.2667 (Figure 2). The coefficient of determination $\left(R^{2}\right)$ of standard hispidulin was found to be 0.9997 , indicating that the analytical method is acceptable. ${ }^{17,18}$ The peak of standard hispidulin was well separated with no interferences at the retention time of $28.18 \mathrm{~min}$ (Figure 3). The HPLC chromatogram of hispidulin in C. petasites root extract was shown in Figure 4. The peak purity index of hispidulin in C. petasites root extract was 1.0000 (Figure 5). This revealed that the method is selective and specific in this study.

The accuracy was demonstrated by recovery method through the spike of standard hispidulin at three different concentrations (20, 40 and $60 \mu \mathrm{g} / \mathrm{mL}$ ) into C. petasites root extracted sample. The result was found to be admissible (88.82-107.69\% recovery) (Table 3) as the percent recovery that is said to be acceptable lies between $80-120 \% .{ }^{15}$ Using the same amount of spiked concentrations, the average values of repeatability precision and intermediate precision were 0.66 and $1.17 \%$ RSD, respectively. The obtained \% RSD in this study was agreeable because it was not more than $15 \%$ RSD, meeting the requirement reported by FDA. ${ }^{19}$

The limit of detection and the limit of quantitation, calculated from the residual standard deviation of regression line and the slope of calibration curve, displayed 2.30 and $7.00 \mu \mathrm{g} / \mathrm{mL}$, respectively. By

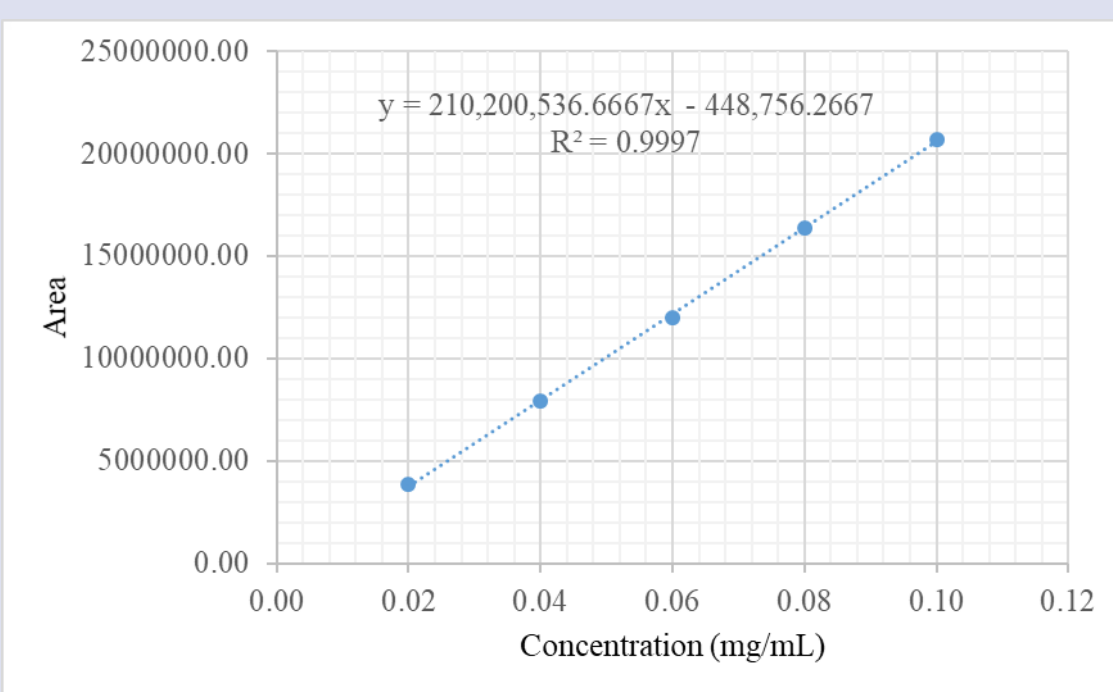

Figure 2: The calibration curve of standard hispidulin. 


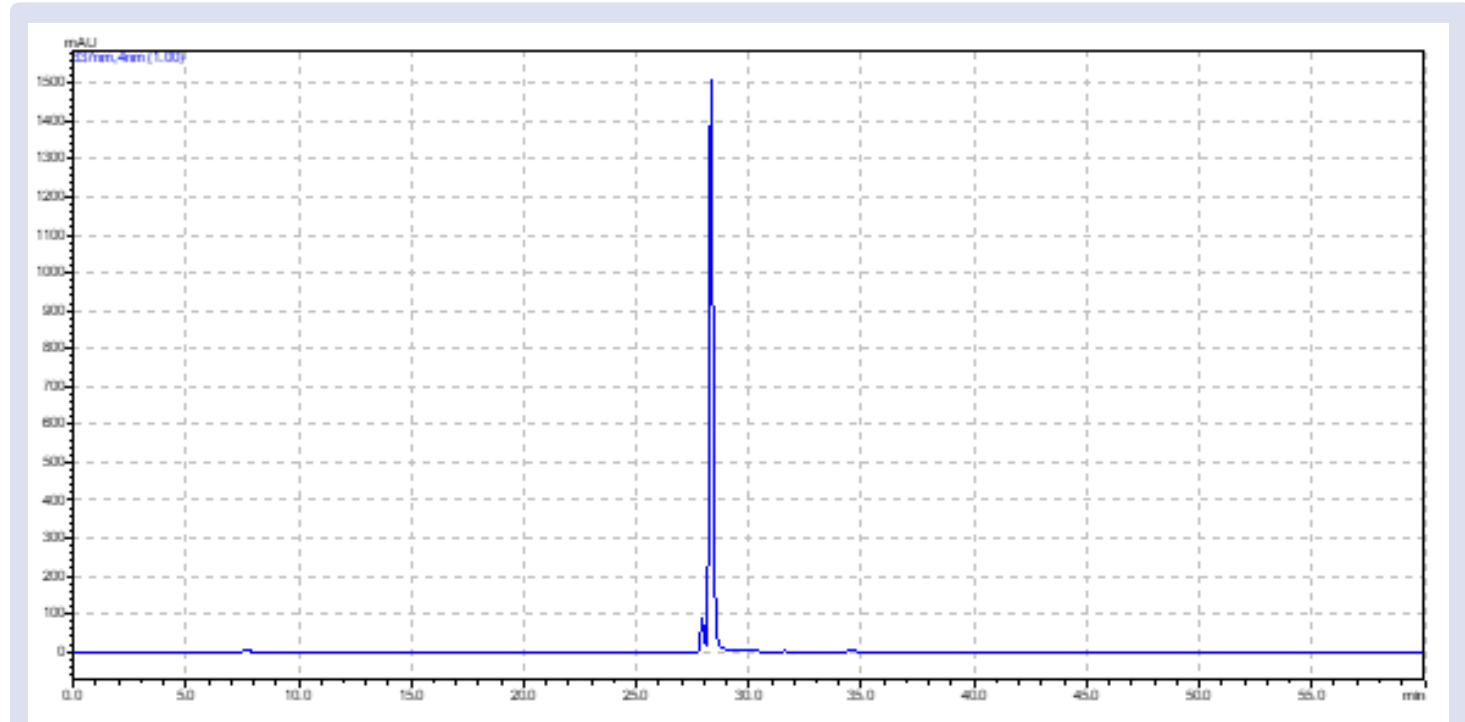

Figure 3: HPLC chromatogram of standard hispidulin at $337 \mathrm{~nm}$.
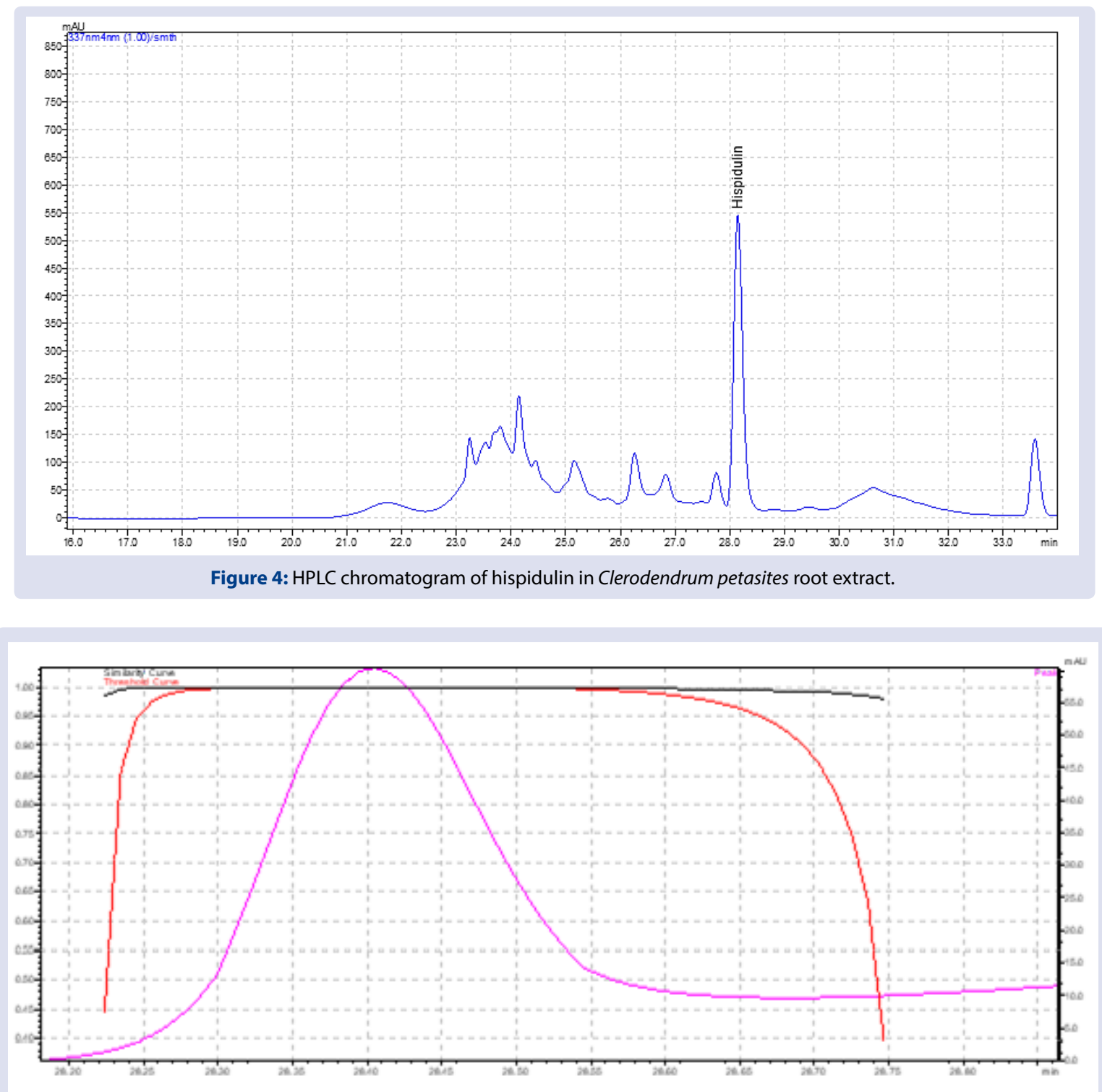

Figure 5: Peak purity of hispidulin in Clerodendrum petasites root extract (Peak purity index: 1.0000). 
Table 3: Accuracy and precision of hispidulin in Clerodendrum petasites root extracts.

\begin{tabular}{cccc}
\hline Level of spiked extract & $\begin{array}{c}\text { Spiked extract }(\mu \mathrm{g} / \mathrm{mL}) \\
(\text { mean } \pm \text { SD) }\end{array}$ & $\begin{array}{c}\text { \% Recovery } \\
(\mathrm{n}=3)\end{array}$ & $\begin{array}{c}\text { R RSD } \\
\text { Repeatability precision }(\mathrm{n}=3)\end{array}$ \\
\hline Unspiked & $23.83 \pm 0.51$ & 88.82 & 2.12 \\
Low & $38.92 \pm 0.09$ & 104.73 & 0.22 \\
Medium & $66.84 \pm 0.14$ & 107.69 & 0.20 \\
High & $90.27 \pm 0.08$ & 0.34 & 0.09 \\
\hline
\end{tabular}

Table 4: Robustness of hispidulin in Clerodendrum petasites root extracts.

\begin{tabular}{ccc}
\hline Temperature & Area & Retention time \\
\hline $34{ }^{\circ} \mathrm{C}$ & $13,372,766$ & 28.25 \\
$35^{\circ} \mathrm{C}$ & $13,255,963$ & 28.18 \\
$36^{\circ} \mathrm{C}$ & $13,445,963$ & 28.13 \\
Average & $13,358,231 \pm 95,830$ & $28.19 \pm 0.063$ \\
\% RSD & 0.72 & 0.22 \\
\hline
\end{tabular}

Table 5: Hispidulin content in Clerodendrum petasites root extracts.

\begin{tabular}{ccccc}
\hline No. & Area of collection & $\begin{array}{c}\text { Yield of extract } \\
(\mathbf{g} / 100 \mathrm{~g} \text { crude drug })\end{array}$ & $\begin{array}{c}\text { Hispidulin in extract }(\mathrm{g} / \mathrm{g}) \\
(\mathbf{n}=3)\end{array}$ & $\begin{array}{c}\text { Hispidulin in crude drug } \\
(\mathbf{g} / 100 \mathrm{~g} \text { crude drug }) \\
(\mathbf{n}=3)\end{array}$ \\
\hline 1 & Yasothon & 7.84 & $0.0036 \pm 0.00010$ & $0.0283 \pm 0.0008$ \\
2 & Lopburi & 6.04 & $0.0065 \pm 0.00021$ & $0.0392 \pm 0.0013$ \\
3 & Nakhon Nayok & 8.47 & $0.0034 \pm 0.00003$ & $0.0285 \pm 0.0003$ \\
4 & Phuket & 6.94 & $0.0022 \pm 0.00002$ & $0.0151 \pm 0.0001$ \\
5 & Lampang & 5.08 & $0.0022 \pm 0.00007$ & $0.0114 \pm 0.0004$ \\
6 & Nong Khai & 13.73 & $0.0008 \pm 0.00002$ & $0.0105 \pm 0.0002$ \\
7 & Phetchabun 1 & 6.69 & $0.0008 \pm 0.00001$ & $0.0053 \pm 0.0001$ \\
8 & Phetchabun 2 & 5.46 & $0.0012 \pm 0.00001$ & $0.0066 \pm 0.0001$ \\
9 & Chachoengsao & 4.74 & $0.0021 \pm 0.00005$ & $0.0098 \pm 0.0002$ \\
10 & Chaiyaphum & 11.86 & $0.0011 \pm 0.00001$ & $0.0134 \pm 0.0002$ \\
12 & Rayong & 5.37 & $0.0039 \pm 0.00008$ & $0.0207 \pm 0.0004$ \\
& Nakhon Pathom & 14.48 & $0.0020 \pm 0.00002$ & $0.0297 \pm 0.0003$ \\
\hline
\end{tabular}

varying the column temperature from $34-36^{\circ} \mathrm{C}$, the results implied that there were insignificant differences $(\% \mathrm{RSD}<1)$ in the retention time, the area under standard curve of hispidulin, and the hispidulin in extracted samples (Table 4). The test for robustness proved the reliability of the method as it remained unaffected by small variations in the method parameters. ${ }^{15}$

The developed HPLC was valid for quantification of hispidulin in $C$. petasites dried root crude drug. As the geographical variation affected the plant secondary metabolites ${ }^{20,21}$, the roots collected from twelve areas were revealed for the hispidulin contents ranged from 0.0053 -0.0392 with the average of $0.0182 \pm 0.0109 \mathrm{~g} / 100 \mathrm{~g}$ by dry weight (Table 5). This finding could be beneficial for the specification of $C$. petasites dried root crude drug in Thailand. The previous study of $C$. petasites aerial part in Thailand demonstrated that hispidulin was the predominant compound $(1.2 \% \mathrm{w} / \mathrm{w}$ in a dried ethanolic extract). Another report showed that hispidulin was the active compound in C. petasites dried aerial part ( $2 \mathrm{~kg}$ ), with the actual yield of $105.12 \mathrm{mg}$ hispidulin. ${ }^{5}$ Hispidulin in C. indicum root was also found but in less content than in C. petasites. It was reported the actual yield of $8.5 \mathrm{mg}$ hispidulin from $1 \mathrm{~kg}$ of $C$. indicum dried root. ${ }^{22,23}$

\section{CONCLUSION}

The RP-HPLC with PDA detector performed in the study was valid for the determination of hispidulin in $C$. petasites dried roots. The hispidulin contents in $C$. petasites dried roots from various areas in Thailand were revealed which could be used for the specification of this crude drug with reference to its chemical marker.

\section{CONFLICTS OF INTEREST}

The authors declare no conflicts of interest.

\section{ACKNOWLEDGEMENT}

The authors are fully supported by the scholarship from "The $100^{\text {th }}$ Anniversary Chulalongkorn University Fund for Doctoral Scholarship" and "The $90^{\text {th }}$ Anniversary Chulalongkorn University Fund (Ratchadaphiseksomphot Endowment Fund)," Graduate School, Chulalongkorn University. The authors wish to express gratitude to College of Public Health Sciences, Chulalongkorn University, and all the staff members for necessary assistance and instrumental support.

\section{REFERENCES}

1. Pichaensoonthon $\mathrm{C}$, Chaowalit $\mathrm{M}$, Jirawong $\mathrm{W}$. The explanation of traditional recipes: Osot-Phra-Na-Rai. 2005.

2. Singharachai $\mathrm{C}$, Palanuvej $\mathrm{C}$, Kiyohara $\mathrm{H}$, Yamada $\mathrm{H}$, Ruangrungsi $\mathrm{N}$ Pharmacognostic specification of five root species in Thai traditional medicine remedy: Ben-Cha-Lo-Ka-Wi-Chian. Pharmacognosy Journal. 2011;3(21):1-11.

3. Robak J, Gryglewski RJ. Bioactivity of flavonoids. Pol J Pharmacol 1996;48(6):555-64

4. Deng W, Fang X, Wu J. Flavonoids function as antioxidants: by scavenging reactive oxygen species or by chelating iron? Radiation Physics and Chemistry. 1997;50(3):271-6.

5. Hazekamp A, Verpoorte $R$, Panthong A. Isolation of a bronchodilator flavonoid from the Thai medicinal plant Clerodendrum petasites. Journal of Ethnopharmacology. 2001;78:45-9.

6. Panthong A, Kanjanapothi D, Taesotikul T, Wongcome T, Reutrakul V. Antiinflammatory and antipyretic properties of Clerodendrum petasites $\mathrm{S}$. Moore. Journal of Ethnopharmacology. 2003;85(1):151-6. 
7. Thitilertdecha P, Guy RH, Rowan MG. Characterisation of polyphenolic compounds in Clerodendrum petasites S. Moore and their potential for topical delivery through the skin. Journal of ethnopharmacology. 2014;154(2):400-7.

8. Syrov VN, Khushbaktova ZA, Abzalora MKh, Sultanov MB. Prospects for the study of flavonoids as hypolipidemic and antiatherosclerotic agents. Doklady Akademii Nauk UzSSR. 1985;3:48-50.

9. Liu L, Xiao X, Zhang L, Jai Z, Li Y, Du M, Zhu Z. Effects of flavones from Saussurea involucrata on DNA synthesis by cancer cells. Lanzhou Daxue Wuebao, Ziran Kexueban. 1985;21:80-3.

10. Liang $X M$, Jin $Y$, Wang YP, Jin GW, Fu Q, Xiao YS. Qualitative and quantitative analysis in quality control of traditional Chinese medicines. Journal of Chromatography A. 2009;1216(11):2033-44.

11. Hertog MG, Hollman PC, Venema DP. Optimization of a quantitative HPLC determination of potentially anticarcinogenic flavonoids in vegetables and fruits. Journal of Agricultural and Food Chemistry. 1992;40(9):1591-8.

12. Proestos C, Sereli D, Komaitis M. Determination of phenolic compounds in aromatic plants by RP-HPLC and GC-MS. Food chemistry. 2006;95(1):44-52.

13. Merken HM, Beecher GR. Measurement of food flavonoids by highperformance liquid chromatography: a review. Journal of Agricultural and Food Chemistry. 2000;48(3):577-99.

14. Govindarajan R, Singh DP, Singh AP, Pandey MM, Rawat AKS. A validated HPLC method for quantification and optimization of furocoumarins in different extracts of fruits of Heracleum candicans. Chromatographia. 2007;66(5-6):401-5.

15. ICH (Q2R1) Validation of analytical procedures: Text and Methodology. Geneva: International Conference on Harmonization, International Conference on Harmonization of Technical Requirements for registration of Pharmaceuticals for Human Use. 2005.
16. European Medicines Agency. Reflection paper on markers used for quantitative and qualitative analysis of herbal medicinal products and traditional herbal medicinal products. 2008 [cited 2019 May 7]. Available from https://www.ema. europa.eu/en/documents/scientific-guideline/draft-reflection-paper-markersused-quantitative-qualitative-analysis-herbal-medicinal-products_en.pdf

17. Thetsana P, Chaowuttikul C, Palanuvej C, Ruangrungsi N. Pharmacognostic specifications, quercetin and quercitrin quantification in Bauhinia malabarica Leaf. Pharmacognosy Journal. 2019;11(1).

18. Duangyod T, Palanuvej C, Ruangrungsi N. Pharmacognostic specifications and quantification of $(+)$-catechin and (-)-epicatechin in Pentace burmanica stem bark. Pharmacognosy Research. 2014;6(3):251.

19. Food and Drug Administration. US Department of Health and Human Services, Guidance for Industry, Bioanalytical Method Validation, FDA. 2001

20. Smriti M, Shashidhara $S$, Rajasekharan PE, Hanumantharaju $N$ Rajendra. CE HPLC analysis of Adhatoda vasica obtained from different geographical sources. International Journal of Drug Development and Research. 2010;2(4):676-80.

21. Kunle OF, Egharevba HO, Ahmadu PO. Standardization of herbal medicines-A review. International Journal of Biodiversity and Conservation. 2012;4(3):101-12.

22. Somwong P, Moriyasu M, Suttisri R. Chemical constituents from the roots of Clerodendrum indicum and Clerodendrum villosum. Biochemical Systematics and Ecology. 2015;63:153-6.

23. Somwong P, Suttisri R. Cytotoxic activity of the chemical constituents of Clerodendrum indicum and Clerodendrum villosum roots. Journal of Integrative Medicine. 2018:16(1):57-61.

\section{GRAPHICAL ABSTRACT}

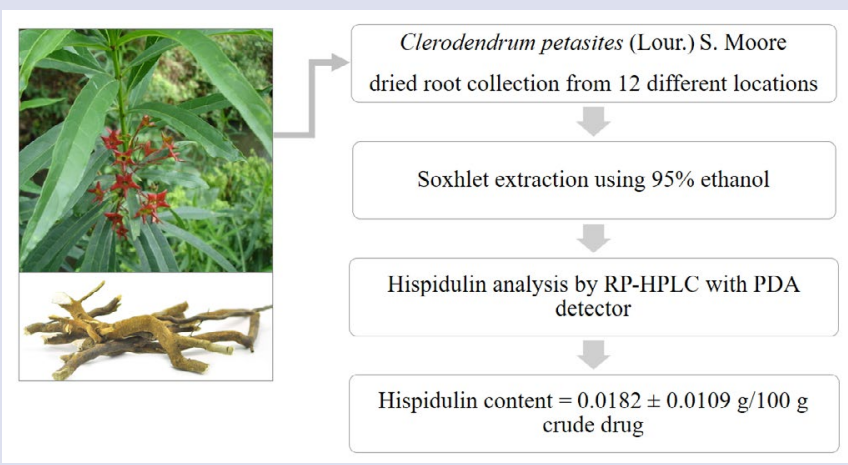

\section{SUMMARY}

- Clerodendrum petasites (Lour.) S. Moore (Mai-ThaoYaai-Mom), belonging to the Verbenaceae family, is widely formulated into Ben-Cha-Lo-Ka-Wi-Chian remedy, possessing antipyretic activity. The flavonoid hispidulin is one of the main active compounds present in $C$. petasites.

- The present study aimed to determine the hispidulin content in the dried roots of $C$. petasites, collected from twelve different areas, using HPLC-PDA technique.

- The optimized HPLC coupling with PDA detector (HPLCPDA) was successfully validated for the quantitative analysis of hispidulin content in $C$. petasites roots in terms of linearity, accuracy, precision, limit of detection, limit of quantitation, specificity and robustness.

- The amount of hispidulin was found to be $0.0182 \pm 0.0109$ $\mathrm{g} / 100 \mathrm{~g}$ crude drug.

- The HPLC-PDA analysis was able to effectively determine hispidulin in $C$. petasites roots, which could be used for the specification of this crude drug with reference to its chemical marker.

\section{ABOUT AUTHORS}

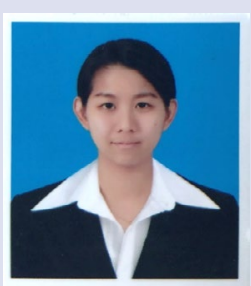

Thanyathorn Tangsongcharoen: She is currently studying Ph.D. at the College of Public Health Sciences, Chulalongkorn University. She graduated her bachelor's degree in applied chemistry, Chulalongkorn University. She has focused her researches on scientific evidence based - traditional Thai and alternative medicines. Her researches involves herbal drug standardization, chemical qualitative/quantitative analyses and biological activity evaluation. 


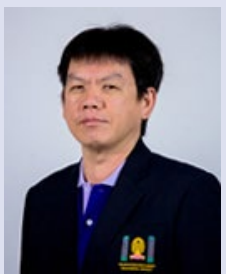

Somchai Issaravanich: He is a researcher at the College of Public Health Sciences, Chulalongkorn University. He has focused his researches on scientific research based on Thai traditional and alternative medicines. His career involves herbal drug standardization, chemical qualitative/ quantitative analyses. He has collaborated with Department for Development of Thai Traditional and Alternative Medicine, Ministry of Public Health for establishing "Pharmacognostic Specification of Thai Crude Drugs" which have been printed as reference books in 2007 (Volume 1) and 2013 (Volume 2).

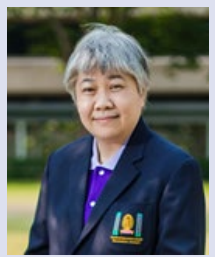

Chanida Palanuvej: She is an Associate Professor at the College of Public Health Sciences, Chulalongkorn University. She has focused her researches on scientific evidence based - traditional Thai and alternative medicines. Her career involves herbal drug standardization, chemical qualitative/ quantitative analyses and biological activity evaluation. She has collaborated with Department for Development of Thai Traditional and Alternative Medicine, Ministry of Public Health for establishing "Pharmacognostic Specification of Thai Crude Drugs" which have been printed as reference books in 2007 (Volume 1) and 2013 (Volume 2).

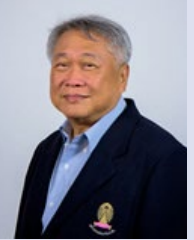

Nijsiri Ruangrungsi: He is an Associate Professor at the College of Public Health Sciences, Chulalongkorn University. He pursued the career of pharmacognosy curriculum as well as research on chemistry of natural products. He has got enormous experiences in plant taxonomy, phytochemistry and herbal medicine. He is an expert in medicinal plants and pharmacognosy of Ministry of Public Health. He is appointed to be a committee in the National Science and Technology Development Board of National Science and Technology Development Agency (NSTDA). He is also an advisory member of National Nanotechnology Center (Nanocosmeceutics).

Cite this article: Tangsongcharoen T, Issaravanich S, Palanuvej C, Ruangrungsi N. Quantitative Analysis of Hispidulin Content in Clerodendrum petasites Roots Distributed in Thailand. Pharmacog J. 2019;11(5):1093-9. 